\title{
1,4NQ-BC enhances the lung inflammation by mediating the secretion of IL-33 which derived from macrophages
}

\section{Xuetao Wei ( $\square$ weixt@bjmu.edu.cn )}

School of Public Health, Peking University

\section{Qianqian Xiao}

Department of Toxicology, School of Public Health, Peking University

\section{Yiming Song}

Department of Toxicology, School of Public Health, Peking University

\section{Hongqian Chu}

Beijing Chest Hospital, Capital Medical University, Beijing

\section{Mengmeng Tang}

Department of Toxicology, School of Public Health, Peking University

\section{Siqi Wang}

Department of Toxicology, School of Public Health, Peking University

\section{Jianjun Jiang}

Department of Toxicology, School of Public Health, Peking University

\section{Qinghe Meng}

Department of Toxicology, School of Public Health, Peking University

\section{Weidong Hao}

Department of Toxicology, School of Public Health, Peking University

\section{Research}

Keywords: IL-33, 1,4NQ-BC, lung inflammation, macrophage

Posted Date: January 2nd, 2020

DOl: https://doi.org/10.21203/rs.2.19746/v1

License: (1) (1) This work is licensed under a Creative Commons Attribution 4.0 International License.

Read Full License 


\section{Abstract}

Background Black carbon (BC) is a product of incomplete combustion of fossil fuels and vegetation. The compelling evidence has demonstrated that it has a close relationship with several respiratory and cardiovascular diseases. BC provides the reactive sites and surfaces to absorb various chemicals, such as polycyclic aromatic hydrocarbons (PAH). Naphthoquinone is a typical PAHs which was found in particulate matter (PM) and 1,4NQ-BC owned high oxidative potential and cytotoxicity. IL-33 is an alarmin which increases innate immunity through Th2 responses. It was reported that IL-33 was a potent inducer of pro-inflammatory cytokines, like IL-6. In our previous study, it was revealed that 1,4NQ-BC instilled intratracheally to mice could trigger zthe lung inflammation and stimulate the secretion of IL-33 in lung tissue.

Results We found that IL-33 could induce inflammation in lung itself. When the macrophages were eliminated, the secretion of IL-33 was reduced and the pathological damage in the lung was relieved after exposure to 1,4NQ-BC. Both MAPK and PI3k/Akt signal pathways were involved in the process of IL-33 secretion and the lung inflammation induced by 1,4NQ-BC.

Conclusions The findings herein support the notion that after exposure to 1,4NQ-BC, the increased secretion of IL-33 was mainly derived from macrophage through both MAPK and PI3k/Akt signal pathways.

\section{Introduction}

Incomplete fuel combustion can produce Black Carbon (BC) or soot particles. They are ubiquitous and play important roles in atmospheric transformation [1]. BC is the second largest contributor to global warming and it is an important constituent of atmospheric particulate matter (PM) [2,3]. It was reported that $\mathrm{BC}$ could accelerate atherosclerotic plaque formation, increased asthma risk and pulmonary inflammation [4-7]. When $\mathrm{BC}$ is emitted into the atmosphere, it undergoes an aging process. During this process, its particle morphology, chemical features and redox activity may be changed [8-10].

$\mathrm{BC}$ has been recognized to catalyze various chemical reactions in the atmosphere such as the formation of nitrous acid, which contributes to photochemical ozone and smog formation [11-13]. It can also provide reactive sites and surfaces for many heterogeneous reactions [14]. Furthermore, BC can absorb polycyclic aromatic hydrocarbons (PAH) during the combustion process. In this sorption progress, BC accompanies with PAH can enhance the toxicity [15]. PAHs are well-recognized as a group of ubiquitous environmental organic pollutants because of its carcinogenicity, teratogenicity and mutagenicity [16]. There are six PAHs have been classified as the priority pollutants by the Environmental Protection Agency in the United States $[17,18]$. It was reported that PM associated fraction of PAHs and most quinones had been found in ambient particulate matter, automotive exhaust emissions and wood smoke particles [1924]. Quinones can act as catalysts to produce reactive oxygen species (ROS) directly and may play a key role in PM toxicity [25]. The evidence suggested that among the three types of $B C$ including 1,4- 
naphthoquinone (1,4-NQ)-coated, sulfate-coated and $\mathrm{O}_{3}$-aged $\mathrm{BC}$, the 1,4-NQ-BC owned the highest oxidative capacities and cytotoxicity [26]. The reports about the toxicity of 1,4NQ-BC were scarce. It was first mentioned that 1,4NQ-BC may cause lung inflammation by our lab and the present study tried to excavate the potential mechanism.

Interleukin (IL)-33 is described as a nuclear-associated cytokine of IL-1 family. It plays its biological function through IL-1 receptor-related protein ST2 and induces T helper type 2-associated cytokines, such as IL-4, IL-5, IL-13 [27, 28]. The mRNA expression of IL-33 was high in various murine tissues, such as the stomach, lung, spinal cord, brain and skin [29]. IL-33 is an alarmin cytokine in innate immunity, inflammation and allergy [30]. When mice were injected with IL-33, the eosinophilia and superoxide anion were induced [27]. IL-33 also activates the mast cells, basophils and it can induce degranulation, maturation, promotes survival and increases the production of several pro-inflammatory cytokines [31, 32]. IL-33 plays a key role in initiating pro-inflammatory responses in mast cells reacting to cell injury [33]. In dendritic cells, IL-33 initiates $\mathrm{T}_{\mathrm{H}}$ 2-type immune responses through ST2 [34]. It profoundly enhances allergic inflammation through increased expression of proallergic cytokines and chemokines [35]. When macrophage RAW264.7 treated with lipopolysaccharide (LPS), IL-33 was induced through cyclic adenosine monophosphate (CAMP)-mediated signaling pathway [36]. In PBMCs derived from smokers treated with soot particles, the expression of IL-33 was increased [37]. IL-33 is crucial for the immune response, as it regulates immune cell infiltration and activation.

In our previous study, it was well acknowledged that after the mice instilled with no matter BC or 1,4NQBC,the secretion of IL-33 in bronchoalveolar lavage fluid (BALF) was significantly increased. The IL-33 neutralizing antibody reversed the lung inflammation partly which induced by $B C[38,39]$. It suggested that IL-33 played a key role in this proinflammatory process. In our in vitro experiments, we also found that the IL-33 mRNA expression in macrophage (RAW264.7) increased, not in epithelial cells at the same level of BC exposure.

Hence, we assume that the macrophage might be the target of 1,4NQ-BC which triggered the lung inflammation and IL-33 might derive from the macrophage. Based on this hypothesis the origin of IL-33 was examined and the underlying mechanism was unveiled in our experiments.

\section{Results}

\section{IL-33 enhanced lung inflammation through MAPK and PI3k/Akt signal pathways}

To determine whether IL-33 played a role in the process of 1,4NQ-BC induced lung inflammation, the first step was to detect whether IL-33 itself could induce lung inflammation. IL-33 was intratracheally instilled to mice twice a week for four weeks. 24 hours after the last instillation, all related items were examined. As shown in Fig. 1A, total cell counts in BALF in mice treated with IL-33was significant higher than that of the control group. 
Histological analysis of lung tissue was provided in Fig. 1B-E. Mice instilled with IL-33 showed marked inflammatory cell infiltration in the lung tissue compared with PBS-treated mice which mainly distributed around the blood vessels, bronchus and pleura. The number of inflammatory cells showed that IL-33 treated group has much more severe lung inflammation compared with the control group (Fig. 1. F-H). Histopathological results testified our original assumption that exogenous IL-33 could induce non-allergic inflammation of the lung.

The phosphorylation of JNK and ERK in lung tissue was increased after exposure to IL-33. Similarly, the expression of $\mathrm{PI} 3 \mathrm{~K}$ and the phosphorylation of Akt in the IL-33 treated group was higher than the control group. All the above indicated that both MAPK and PI3k/Akt signal pathways might play a role in the proinflammatory action of IL-33 (Fig. 1I-J).

IL-33 affected the T cell sub-types in mediastinal lymph nodes

As shown in Fig. 2A, for IL-33 instilled mice, the coefficient of mediastinal lymph nodes was significantly increased compared with the control group. Through flow cytometry analysis, it was shown that the percentage of $\mathrm{CD} 4^{+} \mathrm{T}$ cells in IL-33 treated group was higher than the control group. However, the percentage of $\mathrm{CD}^{+} \mathrm{T}$ cells was lower than the control group. On the other hand, the percentage of Treg cells in IL-33 treated group were higher than the control group (Fig. 3E-F) while the percentage of Th17 had no difference between the IL-33 treated group and the control group (data not show).

The lung inflammation caused by 1,4NQ-BC was reversed after elimination of the macrophages

Our previous in vitro experiments had shown that BC could stimulate mouse leukemia cells of monocyte macrophage RAW264.7 to secrete IL-33(data not show). So we speculated that macrophage might be involved in the process of 1,4NQ-BC induced lung inflammation. In order to confirm whether the inflammation caused by 1,4NQ-BC could relieve without macrophage, cells were knocked out by CLOlipo. As shown in Fig. 3A, CLOlipo deleted the macrophages effectively. Mice were treated as the Methods described. Histopathology analysis was used to examine the function of the macrophage. In Fig. 3B-D, it showed that the inflammation of the lung was rarely observed in PBSlipo group and CLOlipo group. In 1,4NQ-BC treated groups (Fig. 3E-F), representative inflammatory cell recruitment around the blood vessel, bronchus and pleura in the lung were observed. However, after the elimination of the macrophages, inflammatory cells infiltration reduced remarkably. The number of inflammatory cells revealed that the mice treated with CLOlipo \& 1,4NQ-BC has lower lung inflammation compared with PBSlipo \& 1,4NQ-BC group.

Deletion of macrophage inhibited 1,4NQ-BC induced the secretion of IL-33

In our previous research, 1,4NQ-BC enhanced the secretion of cytokines such as IL-1 $\beta$,IL-6 and IL-33 [38]. It has been reported that in some in vitro experiments, some chemicals can stimulate the macrophages to secrete IL-33[36, 40, 41] .To investigate the hypothesis of whether IL-33 derived from macrophages or not, ELISA kits were used to examine the expression of IL-33 after the different treatments. In Fig. 4A, 1,4NQ- 
BC treatment enhanced the secretion of IL-33 in BALF compared with the control group. As expected, deletion of the macrophages reduced the secretion of IL-33 after 1,4NQ-BC treatment. At the same time, the mRNA and protein level of IL-33 in lung tissue were examined. In Fig. 4B-D, in PBSlipo and 1,4NQ-BC treated group, both the mRNA expression and the protein expression of IL-33 were increased compared with the PBSlipo treated group. After abrogating the macrophages, the expression of IL-33 was significantly decreased than PBS \& 1,4NQ-BC group.

Macrophage were involved in T cell sub-typed changes influenced by 1,4NQ-BC treatments

As shown in Fig. 5, in the PBSlipo \& 1, 4NQ-BC group, the percentage of CD4 + T cells in mediastinal lymph nodes was higher than that of the PBSlipo control group. However, for the mice instilled with CLOlipo \& 1, 4NQ-BC, the percentage of CD 4 + T cells was lower compared with PBSlipo \& 1, 4NQ-BC group. The percentage of Treg cells was increased after exposure to 1, 4NQ-BC (Fig. 6). But in CLOlipo \& 1, 4NQ-BC group, when macrophage was deleted, the percentage of Treg cells was significantly decreased compared with PBSlipo \& 1,4NQ-BC group. The percentage of Th17 cells showed no difference among all groups (data not show). Macrophages played a role in the change of T cell sub-types induced by 1, 4NQBC.

IL-33 from macrophage might disturb the MAPK and PI3k/Akt signal pathway after 1,4NQ-BC treatment

In our previous study, we found that 1,4NQ-BC caused lung damage through MAPK and PI3k/Akt signal pathways [39]. It was also verified that MAPK and PI3k/Akt pathways were involved in IL-33 induced lung inflammation above. To confirm the IL-33 come from macrophage when 1, 4NQ-BC given to mice, MAPK and PI3K/Akt signal pathways were examined. In Fig. 7, the expression of phosphorylation of ERK, p-38, JNK and Akt in the PBSlipo \& 1,4NQ-BC group was higher than that of the PBSlipo group. As expected, in CLOlipo \& 1,4NQ-BC group, the phosphorylation of these proteins was reduced compared with the PBSlipo $\& 1,4 \mathrm{NQ}$-BC group. These findings indicated that the IL-33 derived from macrophage were involved in the lung injury caused by $1,4 \mathrm{NQ}-\mathrm{BC}$.

\section{Discussion}

Ambient air pollution and particulate matter have been regarded as a major risk which can induce public health problems including respiratory disease, cancers and heart failure [42]. Many animal experiments demonstrated that $\mathrm{PM}_{2.5}$ exposure triggered pulmonary inflammation [43-45]. As a major component of $\mathrm{PM}_{2.5}$, Black carbon is generated from fossil fuel incomplete combustion, moreover, it can absorb quinones [38]. Quinones and their reductive products can generate ROS species which may be the reason that quinones had a close relationship with adverse health effects [44, 45]. In our previous study, we offered the evidence that 1,4NQ-BC could trigger the lung inflammation accompanied by high expression of IL-33[38]. But if mice were treated with IL-33 neutralizing antibody together with black carbon, the lung inflammation was alleviated compared with the black carbon itself $[39,46]$. Hence, it was speculated that 
IL-33 may play a crucial role in this progress. Firstly, it is important to confirm whether IL-33 could stimulate lung inflammation itself or not.

As a member of the IL-1 family, Interleukin-33 mediates its biological function through the ST2 receptor [47]. Emerging evidence suggests that IL-33 has a close relationship with airway inflammation and allergic diseases $[33,48]$. It was required for ovalbumin- and papain- induced type 2 airway inflammation. IL-33 induction occurred in both hematopoietic and non-hematopoietic cells, particularly in alveolar type 2 cells [35]. It was found that mice injected intraperitoneally with IL-33 induced splenomegaly and the increased with the IgE [27]. IL-33 could mediate the inflammatory responses in lung tissue cells, especially in human microvascular endothelial cells from lung blood vessels (HMVEC-LB1) [49]. It was noteworthy that, in vivo, we got the evidence that mice intratracheally instilled with IL-33 showed pathological damage in the lung including the severe inflammation around the blood vessel, bronchus and pleura. The higher total cells in BALF and coefficient of mediastinal lymph nodes emphasized the pro-inflammatory action of IL-33. Several in vitro experiments indicated that IL-33 could enhance MAPK (ERK and p38) phosphorylation in murine, human mast cells and microvascular endothelial cells [27, 49-51]. It was a promoter in cell injury in human mast cells through MAPK pathways [33, 52]. IL-33 has also been reported to be an activator in PI3k/Akt signal pathway in cardiomyocyte, primary trophoblasts. $[53,54]$.These results were limited to in vitro experiments, in vivo, we confirmed IL-33 induced inflammation through MAPK and Akt pathways in lung. MAPK and PI3k/Akt signal pathways were provoked in lung tissues after IL-33 instillation. Hence, it was presented the evidence that IL-33 could stimulate lung inflammation via activating MAPK and PI3k/Akt signal pathways. Considering the consistent evidence between 1,4NQBC and IL-33, it was hypothesized that 1,4NQ-BC might trigger lung inflammation through IL-33 secretion.

To further verify the new idea, the origin of IL-33 was explored after 1,4NQ-BC instillation in mice. In our previous in vitro study, it was found that BC could stimulate RAW264.7 cells to secrete IL-33 but had no effect on the human bronchial epithelial cells $16 \mathrm{HBE}$ (data now shown). It implied that macrophage might be the source of IL-33. In order to prove the importance of macrophage on the origin of IL-33 after 1,4NQ-BC treatment, mice were instilled with Clodronate liposome intratracheally to eradicate the macrophage in the lung. [55-57]. As expected, after the effective abrogation of the macrophages, the mRNA and protein expression of IL-33 in lung tissue significantly reduced accompanied by the alleviation of the lung damage.

It has been reported that IL-33 could enhance the differentiation of Treg cell subsets [58]. Administration of recombinant IL-33 contributed to a significant increase in the frequency and the total number of splenic Treg cells $[59,60]$. In line with previous published results, it was verified that intratracheally instillation with IL-33 in mice led to an increase in mediastinal lymph nodes Treg cells in vivo. Thus 1 , 4NQ-BC could enhance the CD4 $4^{+}$cells towards to Treg cells. It was reasonable that this progress might be involved in IL-33 pathway. After elimination of macrophage, the secretion of IL-33 reduced and so as the percentage of Treg cells after 1,4NQ-BC treatment. Interestingly, in CLOlipo treated group, the percentage of Treg cells was increased. It presented that some non-IL-33 dependent pathways participated in the 
progress of macrophage mediated Treg cells differentiation. And the interaction between 1,4NQ-BC and Treg differentiation had already been extrapolated and it will be published in another article.

Moreover, the MAPK and PI3k/Akt signal pathways were inhibited after elimination of macrophage during $1,4 \mathrm{NQ}-\mathrm{BC}$ treatment. It was realized that as the abrogation of macrophage partly reversed the lung inflammation induced by 1,4NQ-BC, there must be some other cytokines involved in the proinflammatory progress. Herein, our findings support the notion that IL-33 most possibly derived from the macrophage in the lung exposed to 1,4NQ-BC.

\section{Conclusions}

In this work, IL-33 was proved to induce lung inflammation itself. Both MAPK and PI3K/Akt pathways took part in the proinflammatory process. IL-33 had the ability to change the T cell subtypes. Moreover, 1 , $4 N Q-B C$ triggered the lung inflammation. The underlying mechanisms needed to be explored. CLOlipo was used to get rid of the influence of macrophage and help to explore the origin of IL-33 after 1,4NQ-BC treatment. Based on the pathological results and related protein expression, it was unveiled that IL-33 might derive from macrophage which played a key role in the process of 1,4NQ-BC mediated lung inflammation. Our findings provide new insight into the function and origin of IL-33 in PM induced lung inflammation.

\section{Methods}

\section{Animals}

All the animals used in this study were healthy female C57BL/6 $(18 \sim 20 \mathrm{~g})$ purchased from Charles River Laboratories Co. Ltd. (Beijing, China) and raised under a specific pathogen-free condition with a barrier system (temperature: $20-26^{\circ} \mathrm{C}$, relative humidity: $40-70 \%$ ). Standard mice feed and tap water were available. All animals in this study were approved by the Ethics Committee of Peking University. All of the methods were conducted in accordance with the relevant guidelines by the above Ethics Committee.

\section{1,4NQ-BC}

BC and 1, 4 -naphthoquinone were provided by Professor Jing Shang (College of Environmental Sciences and Engineering, Peking University). Printex U black carbon (UBC) was obtained from Deussa which was one of the most representative diesel soot (61). $0.05 \mathrm{~g} 1$, 4-naphthoquinone and $1 \mathrm{~g}$ of BC were blended and dissolved in dichloromethane. The mixture was dried at $60^{\circ} \mathrm{C}$ for $4 \mathrm{~h}$ after rotary evaporation to get 1,4NQ-BC (26). The particles were suspended in the saline, and then sonicated for 15 min before intratracheal instillation.

\section{Experimental design}

Two animal experiments were conducted in this study. One is that the mice were divided into two groups: PBS control group and IL-33 (Thermo Fisher Scientific, USA) treated group ( $n=8$, the total number is 28 ). 
IL-33 was instilled in $0.4 \mu \mathrm{g}$ per mouse, twice a week for four weeks.

The other animal experiment is that mice were divided into 5 groups: negative control, PBSliposome control (Liposoma, Holland), Clodronateliposome (Liposoma, Holland), PBSliposome \& 1,4NQ-BC group and Clodronateliposome \& 1,4NQ-BC group ( $n=8$ per group). The Clodronateliposome was aimed to eliminate macrophages. The $0.06 \mathrm{ml}$ dissolved particles were instilled to per mouse, twice a week for four weeks. $24 \mathrm{~h}$ after the last instillation, the body weight of each mouse and the organ coefficient were measured. The animals were sacrificed by cervical dislocation after isoflurane anesthesia.

\section{Intratracheal instillation}

All mice were anesthetized by an intraperitoneal injection of $5 \%$ chloral hydrate $(0.1 \mathrm{ml} / 10 \mathrm{~g}$ body weight $)$.

IL-33 treated group ( $\mathrm{n}=8)$ : Mice were instilled with a volume of $0.06 \mathrm{ml} 0.4 \mu \mathrm{g}$ via a cannula, followed by $0.8 \mathrm{ml}$ of air. $0.06 \mathrm{ml}$ of PBS were instilled to the control group.

PBSliposome (PBSlipo) and Clodronateliposome (CLOlipo) groups ( $n=8)$ : Mice were instilled with PBSliposome $(0.04 \mathrm{ml})$ or Clodronateliposome $(0.04 \mathrm{ml})(55-57)$ two days earlier before the groups treated with 1,4NQ-BC. PBSliposome group was set as solvent control.

1,4NQ-BC with PBSliposome or Clodronateliposome groups $(n=8)$ : Mice were separately instilled PBSliposome or Clodronateliposome two days earlier before the mice were instilled the particles. The mice were instilled with a volume of $0.06 \mathrm{ml} 200 \mu \mathrm{g}$ 1,4NQ-BC suspensions via a cannula, followed by $0.08 \mathrm{ml}$ of air. The negative control group was left untreated.

\section{Bronchoalveolar lavage and cell differentials}

All mice were anesthetized with $0.1 \mathrm{ml} / 10 \mathrm{~g}$ of $5 \%$ chloral hydrate and the lungs were gently lavaged with $1 \mathrm{ml}$ PBS for 3 times. The collected lavage was centrifuged (300x g, 10min) and supernatants were obtained and then stored at $-80^{\circ} \mathrm{C}$ to measure the cytokines. The cell sediments from the lavages were resuspended in $1 \mathrm{ml}$ of PBS containing 1\% BSA. Cells were counted by Counter Star (Shanghai, China). After then they were smeared to slides then stained by using Diff Quick (American Scientific Inc., Sewickly, PA). 300 cells were counted and the macrophages were identified.

\section{ELISA analysis}

The level of IL-33 in bronchoalveolar lavage fluid was detected by commercial enzyme-linked immunosorbent assay (ELISA) kits (Abcam Co. Ltd. UK). All the procedures were conducted according to the manufacturer's instructions.

\section{Quantitative PCR}

Total RNA was extracted from the lungs for the generation of single-stranded CDNA and PCR was performed. The SYBR Green kit (TakaRa, DRR041A) was used in the quantitative realtime PCR. The 
reaction was performed according to the standard protocol in the IQTM5 Multicolor Real-Time PCR Detection System (Bio-RAD). The primers used for each gene were as follows: the endogenous control was glyceraldehyde-3-phosphate dehydrogenase (forward: 5'-GCTGAGTATCGTGAGT-3', reverse: 5'GTTCACACCCATCACAAAC-3') and IL-33 (forward: 5'- GGTGCTACTACGCTACTATG-3', reverse: 5'GATGTCTGTGTCTTTGATGG-3')

\section{Western blot analysis}

Western blot analysis was performed as described in our previous study $[38,46]$. Briefly, the lung tissue was weighed and homogenized in ice-cold lysis buffer and lysed for $30 \mathrm{~min}$ at $4{ }^{\circ} \mathrm{C}$. Equal amounts of sample proteins were separated by $10 \%$ SDS-PAGE, followed by transfer to a polyvinylidene difluoride membrane. The membranes were incubated with the primary antibodies overnight at $4{ }^{\circ} \mathrm{C}$. The primary antibodies were used at dilutions of 1:100 to 1:1000. Secondary antibodies conjugated to HRP were added and detected with a chemiluminescent substrate. $\beta$-actin was used as an internal control of equal protein loading.

\section{Organ coefficient and flow cytometry analysis}

Mediastinal lymph nodes were separated and weighed. Organ coefficient was the weight of the organ divided by the body weights. Mediastinal lymph nodes were ground into single-cell suspensions and the cells were stained with florescence-conjugated monoclonal antibodies, including CD3-PE, CD4-PECY5, CD8-FITC, FOXP3-FITC. The antibodies were purchased from eBioscience. Cell sub-types were analyzed by Beckman Coulter Flow Cytometer.

\section{Histological assessment of lung tissue}

Lung tissues were separated and fixed in $10 \%$ buffered formalin and then embedded in paraffin. Each specimen was stained with hematoxylin and eosin. The infiltration of lymphocytes was used to determine the severity of the inflammation.

\section{Statistical analysis}

The experimental results are expressed as the mean \pm SD. One-way analysis of variance (ANOVA) followed by Dunnett t-test (SPSS 13.0 Peking University) was used to compare the differences of more than two groups. Differences were considered statistically significant at a P value of less than 0.05 .

\section{Abbreviations}

1, 4NQ-BC: 1, 4Napthoquinone-Black Carbon; Interleukin-33: IL-33; PBSlipo: PBSliposome; CLOlipo: Clodronateliposome; PAH: Polycyclic Aromatic Hydrocarbons; PM: Particulate Matter;

\section{Declarations}


Acknowledgements

The authors thank Professor Jing Shang (College of Environmental Sciences and Engineering, Peking University) for her encouraging support and valuable facilities to carry out this work.

\section{Authors' contributions}

XW, QX, YS and HC designed and performed the experiments. QX and HC wrote the manuscript. MT performed the flow cytometer experiments and western blot experiments. JJ and QM supervised the study. WH revised the manuscript. All authors read and approved the final manuscript.

\section{Funding}

This work was supported by the Natural Science Foundation of China (CN) (Grant No. 91743114).

\section{Ethics approval}

All animal procedures were approved by the Animal Care Committee of the Peking University according to government guidelines for animal care.

\section{Availability of data and materials}

The datasets used and/or analyzed during the current study are available from the corresponding author on reasonable request.

\section{Consent for publication}

Not applicable.

\section{Competing interests}

The authors declare that they have no competing interest.

\section{Author details}

${ }^{a}$ Department of Toxicology, School of Public Health, Peking University, Beijing, P. R. China. ${ }^{b}$ Beijing Key Laboratory of Toxicological Research and Risk Assessment for Food Safety, Beijing, P. R. China. ${ }^{\mathrm{C}}$ Translational Medicine Laboratory, Beijing Chest Hospital, Capital Medical University, Beijing, China. ${ }^{d}$ Beijing Key Laboratory for Drug Resistance Tuberculosis Research, Beijing Tuberculosis and Thoracic Tumor Research Institute, Beijing 101149, P. R. China.

\section{References}

1. 
Koelmans AA, Jonker MT, Cornelissen G, Bucheli TD, Van Noort PC, Gustafsson O. Black carbon: the reverse of its dark side. Chemosphere. 2006;63(3):365-77.

2.

Jacobson MZ. Strong radiative heating due to the mixing state of black carbon in atmospheric aerosols. Nature. 2001;409(6821):695-7.

3.

Mok J, Krotkov NA, Arola A, Torres O, Jethva H, Andrade M, Labow G, Eck TF, Li Z, Dickerson RR, Stenchikov GL, Osipov S, Ren X. Impacts of brown carbon from biomass burning on surface UV and ozone photochemistry in the Amazon Basin. Sci Rep. 2016;6:36940.

4.

Smith KR, Jerrett M, Anderson HR, Burnett RT, Stone V, Derwent R, Atkinson RW, Cohen A, Shonkoff SB, Krewski D, Pope CA 3rd, Thun MJ, Thurston G. Public health benefits of strategies to reduce greenhousegas emissions: health implications of short-lived greenhouse pollutants. Lancet. 2009;374(9707):2091103.

5 .

Clark NA, Demers PA, Karr CJ, Koehoorn M, Lencar C, Tamburic L, Brauer M. Effect of early life exposure to air pollution on development of childhood asthma. Environ Health Perspect. 2010;118(2):284-90.

6.

Delfino RJ, Tjoa T, Gillen DL, Staimer N, Polidori A, Arhami M, Jamner L, Sioutas C, Longhurst J. Trafficrelated air pollution and blood pressure in elderly subjects with coronary artery disease. Epidemiology. 2010;21(3):396-404.

7.

Kim JJ, Smorodinsky S, Lipsett M, Singer BC, Hodgson AT, Ostro B. Traffic-related air pollution near busy roads: the east bay children's respiratory health study. Am J Respir Crit Care Med. 2004;170(5):520-6. 8.

Verma V, Zhang N, Cho AK, Schauer JJ, Shafer MM, Sioutas C. Redox activity of urban quasi-ultrafine particles from primary and secondary sources. Atmos Environ. 2009;43(40):6360-8.

9.

Li QF, Wyatt A, Kamens RM. Oxidant generation and toxicity enhancement of aged-diesel exhaust. Atmos Environ. 2019;43(5):1037-42.

10.

Rattanavaraha W, Rosen E, Zhang HF, Li QF, Pantong K, Kamens RM. The reactive oxidant potential of different types of aged atmospheric particles: An outdoor chamber study. Atmos Environ. 2011:45(23):3848-55.

11.

Amman M, Kalberer M, Jost DT, Tobler L, Rossler E, Piguet D, Gaggeler HW, Baltensperger U. Heterogeneous production of nitrous acid on soot in polluted air masses. Let to nat. 1998;395:157-60. 12.

Buseck PR, Pósfai M. Airborne minerals and related aerosol particles: effects on climate and the environment. Proc Natl Acad Sci USA. 1999;96(7):3372-9. 
13.

Cochrane MA. Fire science for rainforests. Nature. 2003;421(6926):913-9.

14.

Li Q, Shang J, Zhu T. Physicochemical characteristics and toxic effects of ozone-oxidized black carbon particles. Atmos Environ. 2013;81:68-75.

15.

Lohmann R, Macfarlane JK, Gschwend PM. Importance of black carbon to sorption of native PAHs, PCBs, and PCDDs in Boston and New York harbor sediments. Environ Sci Technol. 2005;39(1):141-8.

16.

Han J, Liang Y, Zhao B, Wang Y, Xing F, Qin L. Polycyclic aromatic hydrocarbon (PAHs) geographical distribution in China and their source, risk assessment analysis. Environ Pollut. 2019;251:312-27.

17.

Qin LB, Han J, Zhan YQ, Chen WS, Kim H. Reduction of polycyclic aromatic hydrocarbon emission by porous alumina bed material during sewage sludge incineration. Energy Fuels. 2016;30:544-50.

18.

Hu TP, Zhang JQ, Ye C, Zhang XL, Zhang Y, Wang YK, Sun W, Qin SH, Zhang QF. Status, source and health risk assessment of polycyclic aromatic hydrocarbons (PAHs) in soil from the water-level-fluctuation zone of the Three Gorges Reservoir, China. J Geochem Explor. 2017;172:20-8.

19.

Allen JO, Dooke ran ND, Taghizadeh K, Lafleur AL, Smith KA, Sarofim AF. Measurement of oxygenated polycyclic aromatic hydrocarbons associated with a size-segregated urban aerosol. Environ Sci Technol. 1997;31:2064-70.

20.

Fraser MP, Cass GR, Simoneit BR, Rasmussen RA. Air quality model evaluation data for organics. 5. C6C22 nonpolar and semipolar aromatic compounds. Environ Sci Technol. 1998;32:1760-70. 21.

Simoneit BRT, Sheng GY, Chen XY, Fu JM, Zhang J, Xu YP. Molecular marker study of extractable organicmatter in aerosols from urban areas of China. Atmos Environ. 1991;25:2111-29.

22.

Schuetzle D, Lee FS, Prater TJ. The identification of polynuclear aromatic hydrocarbon (PAH) derivatives in mutagenic fractions of diesel particulate extracts. Int J Environ Anal Chem. 1981;9(2):93-144.

23.

Fine PM, Cass GR, Simoneit BR. Chemical characterization of fine particle emissions from fireplace combustion of woods grown in the northeastern United States. Environ Sci Technol. 2001;35(13):266575.

24.

Ramdahl T. Characterization of polar compounds such as polycyclic aromatic ketones in air-pollution including wood smoke. Environ Int. 1985;11:197-203.

25. 
Li N, Sioutas C, Cho A, Schmitz D, Misra C, Sempf J, Wang M, Oberley T, Froines J, Nel A. Ultrafine particulate pollutants induce oxidative stress and mitochondrial damage. Environ Health Perspect. 2003;111(4):455-60.

26.

Li Q, Shang J, Liu J, Xu WW, Xiang F, Li R, Zhu T. Physicochemical characteristics, oxidative capacities and cytotoxicities of sulfate-coated, 1,4-NQ-coated and ozone-aged black carbon particles. Atmos Res. 2015;153:535-42.

27.

Schmitz J, Owyang A, Oldham E, Song Y, Murphy E, McClanahan TK, Zurawski G, Moshrefı M, Qin J, Li X, Gorman DM, Bazan JF, Kastelein RA. IL-33, an interleukin-1-like cytokine that signals via the IL-1 receptorrelated protein ST2 and induces T helper type 2-associated cytokines. Immunity. 2005;23(5):479-90. 28.

Carriere V, Roussel L, Ortega N, Lacorre DA, Americh L, Aguilar L, Bouche G, Girard JP. IL-33, the IL-1-like cytokine ligand for ST2 receptor, is a chromatin-associated nuclear factor in vivo. Proc Natl Acad Sci USA. 2007;104(1):282-7.

29.

Ohno T, Oboki K, Kajiwara N, Morii E, Aozasa K, Flavell RA, Okumura K, Saito H, Nakae S. Caspase-1, caspase-8, and calpain are dispensable for IL-33 release by macrophages. J Immunol. 2009;183(12):7890-7.

30 .

Cayrol C, Girard JP. IL-33: an alarmin cytokine with crucial roles in innate immunity, inflammation and allergy. Curr Opin Immunol. 2014;31:31-7.

31.

Schneider E, Petit-Bertron AF, Bricard R, Levasseur M, Ramadan A, Girard JP, Herbelin A, Dy M. IL-33 activates unprimed murine basophils directly in vitro and induces in vivo expansion indirectly by promoting hematopoietic growth factor production. J Immunol. 2009;183(6):3591-7.

32.

likura M, Suto H, Kajiwara N, Oboki K, Ohno T, Okayama Y, Saito H, Galli SJ, Nakae S. IL-33 can promote survival, adhesion and cytokine production in human mast cells. Lab Invest. 2007;87(10):971-8. 33.

Enoksson M, Lyberg K, Möller-Westerberg C, Fallon PG, Nilsson G, Lunderius-Andersson C. Mast cells as sensors of cell injury through IL-33 recognition. J Immunol. 2011;186(4):2523-8.

34.

Rank MA, Kobayashi T, Kozaki H, Bartemes KR, Squillace DL, Kita H. IL-33-activated dendritic cells induce an atypical TH2-type response. J Allergy Clin Immunol. 2009;123(5):1047-54.

35 .

Oboki K, Nakae S, Matsumoto K, Saito H. IL-33 and airway inflammation. Allergy Asthma Immunol Res. 2011;3(2):81-8.

36. 
Sato S, Yanagawa Y, Hiraide S, lizuka K. Cyclic AMP signaling enhances lipopolysaccharide sensitivity and interleukin-33 production in RAW264.7 macrophages. Microbiol Immunol. 2016;60(6):382-9.

37.

De Falco G, Terlizzi M, Sirignano M, Commodo M, D'Anna A, Aquino RP, Pinto A, Sorrentino R. Human peripheral blood mononuclear cells (PBMCs) from smokers release higher levels of IL-1-like cytokines after exposure to combustion-generated ultrafine particles. Sci Rep. 2017;7:43016.

38.

Chu H, Shang J, Jin M, Chen Y, Pan Y, Li Y, Tao X, Cheng Z, Meng Q, Li Q, Jia G, Zhu T, Hao W, Wei X. Comparison of lung damage in mice exposed to black carbon particles and 1,4-naphthoquinone coated black carbon particles. Sci Total Environ. 2017;580:572-81.

39.

Chu H, Hao W, Cheng Z, Huang Y, Wang S, Shang J, Hou X, Meng Q, Zhang Q, Jia L, Zhou W, Wang P, Jia G, Zhu T, Wei X. Black carbon particles and ozone-oxidized black carbon particles induced lung damage in mice through an interleukin-33 dependent pathway. Sci Total Environ. 2018;644:218-28.

40 .

Mizutani N, Nabe T, Yoshino S. Interleukin-33 and alveolar macrophages contribute to the mechanisms underlying the exacerbation of IgE-mediated airway inflammation and remodelling in mice. Immunology. 2013;139(2):205-18.

41.

Verma A, Kroetz DN, Tweedle JL, Deepe GS Jr. Type Il cytokines impair host defense against an intracellular fungal pathogen by amplifying macrophage generation of IL-33. Mucosal Immunol. 2015;8(2):380-9.

42.

Yue W, Tong L, Liu X, Weng X, Chen X, Wang D, Dudley SC, Weir EK, Ding W, Lu Z, Xu Y, Chen Y. Short term Pm2.5 exposure caused a robust lung inflammation, vascular remodeling, and exacerbated transition from left ventricular failure to right ventricular hypertrophy. Redox Biol. 2019. doi:10.1016/j.redox.2019.101161.

43.

Klaus V, Hartmann T, Gambini J, Graf P, Stahl W, Hartwig A, Klotz LO. 1,4-Naphthoquinones as inducers of oxidative damage and stress signaling in $\mathrm{HaCaT}$ human keratinocytes. Arch Biochem Biophys. 2010;496(2):93-100.

44.

Watanabe N, Forman HJ. Autoxidation of extracellular hydroquinones is a causative event for the cytotoxicity of menadione and DMNQ in A549-S cells. Arch Biochem Biophys. 2003;411(1):145-57. 45.

Xia T, Korge P, Weiss JN, Li N, Venkatesen MI, Sioutas C, Nel A. Quinones and aromatic chemical compounds in particulate matter induce mitochondrial dysfunction: implications for ultrafine particle toxicity. Environ Health Perspect. 2004;112(14):1347-58.

46. 
Chu H, Shang J, Jin M, Li Q, Chen Y, Huang H, Li Y, Pan Y, Tao X, Cheng Z, Meng Q, Jia G, Zhu T, Wei X, Hao W. Comparison of lung damage in mice exposed to black carbon particles and ozone-oxidized black carbon particles. Sci Total Environ. 2016;(573):303-12.

47.

Johansson K, McSorley HJ. Interleukin-33 in the developing lung-Roles in asthma and infection. Pediatr Allergy Immunol. 2019;30(5):503-10.

48.

Molofsky AB, Savage AK, Locksley RM. Interleukin-33 in Tissue Homeostasis. Injury Inflammation Immunity. 2015;42(6):1005-19.

49.

Yagami A, Orihara $\mathrm{K}$, Morita $\mathrm{H}$, et al. IL-33 mediates inflammatory responses in human lung tissue cells. J Immunol. 2010;185(10):5743-50.

50 .

Saluja R, Hawro T, Eberle J, Church MK, Maurer M. Interleukin-33 promotes the proliferation of mouse mast cells through ST2/MyD88 and p38 MAPK-dependent and Kit-independent pathways. J Biol Regul Homeost Agents. 2014;28(4):575-85.

51.

Yu X, Hu Z, Shen X, Dong L, Zhou W, Hu W. IL-33 Promotes gastric cancer cell invasion and migration via ST2-ERK1/2 pathway. Dig Dis Sci. 2015;60(5):1265-72.

52.

Guarda G, Zenger M, Yazdi AS, et al. Differential expression of NLRP3 among hematopoietic cells. J Immunol. 2011;186(4):2529-34.

53.

Sanada S, Hakuno D, Higgins LJ, Schreiter ER, McKenzie AN, Lee RT. IL-33 and ST2 comprise a critical biomechanically induced and cardioprotective signaling system. J Clin Invest. 2007;117(6):1538-49. 54.

Fock V, Mairhofer M, Otti GR, Hiden U, Spittler A, Zeisler H, Fiala C, Knöfler M, Pollheimer J. Macrophagederived IL-33 is a critical factor for placental growth. J Immunol. 2013;191(7):3734-43.

55 .

Strickland DH, Thepen T, Kees UR, Kraal G, Holt PG. Regulation of T-cell function in lung tissue by pulmonary alveolar macrophages. Immunology. 1993;80(2):266-72.

56.

Van Rooijen N, Sanders A. Liposome mediated depletion of macrophages: mechanism of action, preparation of liposomes and applications. J Immunol Methods. 1994;174(1-2):83-93.

57.

Rooijen NV. The liposome-mediated macrophage 'suicide' technique. J Immunol Methods. 1989;124:1-6. 58.

Peine M, Marek RM, Löhning M. IL-33 in T cell differentiation, function, and immune homeostasis. Trends Immunol. 2016;37(5):321-33.

59. 
Schiering C, Krausgruber T, Chomka A, Fröhlich A, Adelmann K, Wohlfert EA, Pott J, Griseri T, Bollrath J, Hegazy AN, Harrison OJ, Owens BMJ, Löhning M, Belkaid Y, Fallon PG, Powrie F. The alarmin IL-33 promotes regulatory T-cell function in the intestine. Nature. 2014;513(7519):564-8.

60.

Turnquist HR, Zhao Z, Rosborough BR, Liu Q, Castellaneta A, Isse K, Wang Z, Lang M, Stolz DB, Zheng XX, Demetris AJ, Liew FY, Wood KJ, Thomson AW. IL-33 expands suppressive CD11 b + Gr-1 (int) and regulatory T cells, including ST2L + Foxp 3 + cells, and mediates regulatory $T$ cell-dependent promotion of cardiac allograft survival. J Immunol. 2011;187(9):4598-610.

\section{Figures}


A

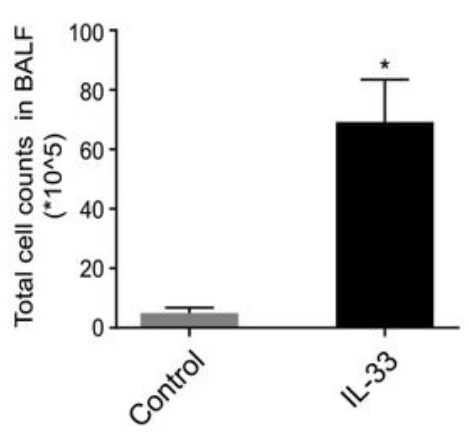

C

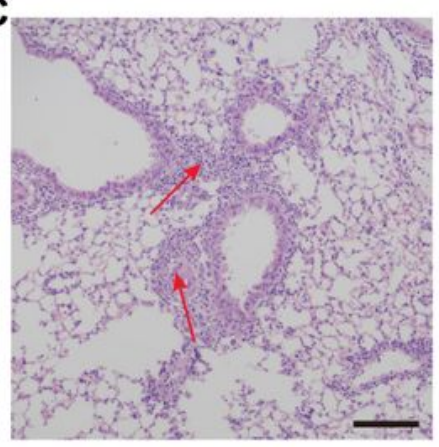

$\mathbf{F}$

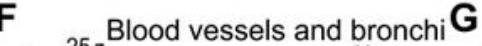

D

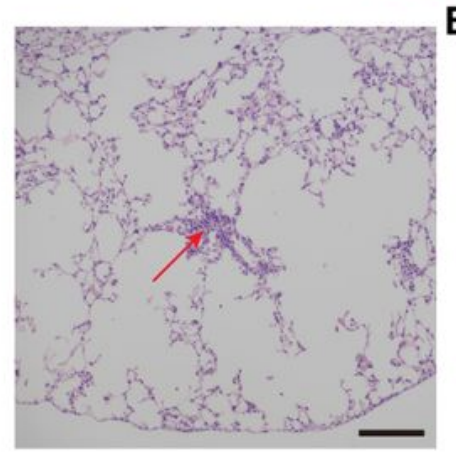

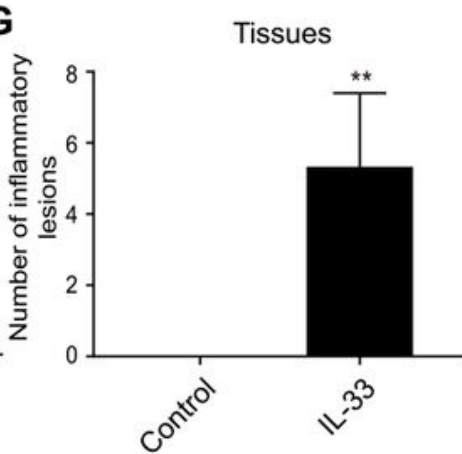

H
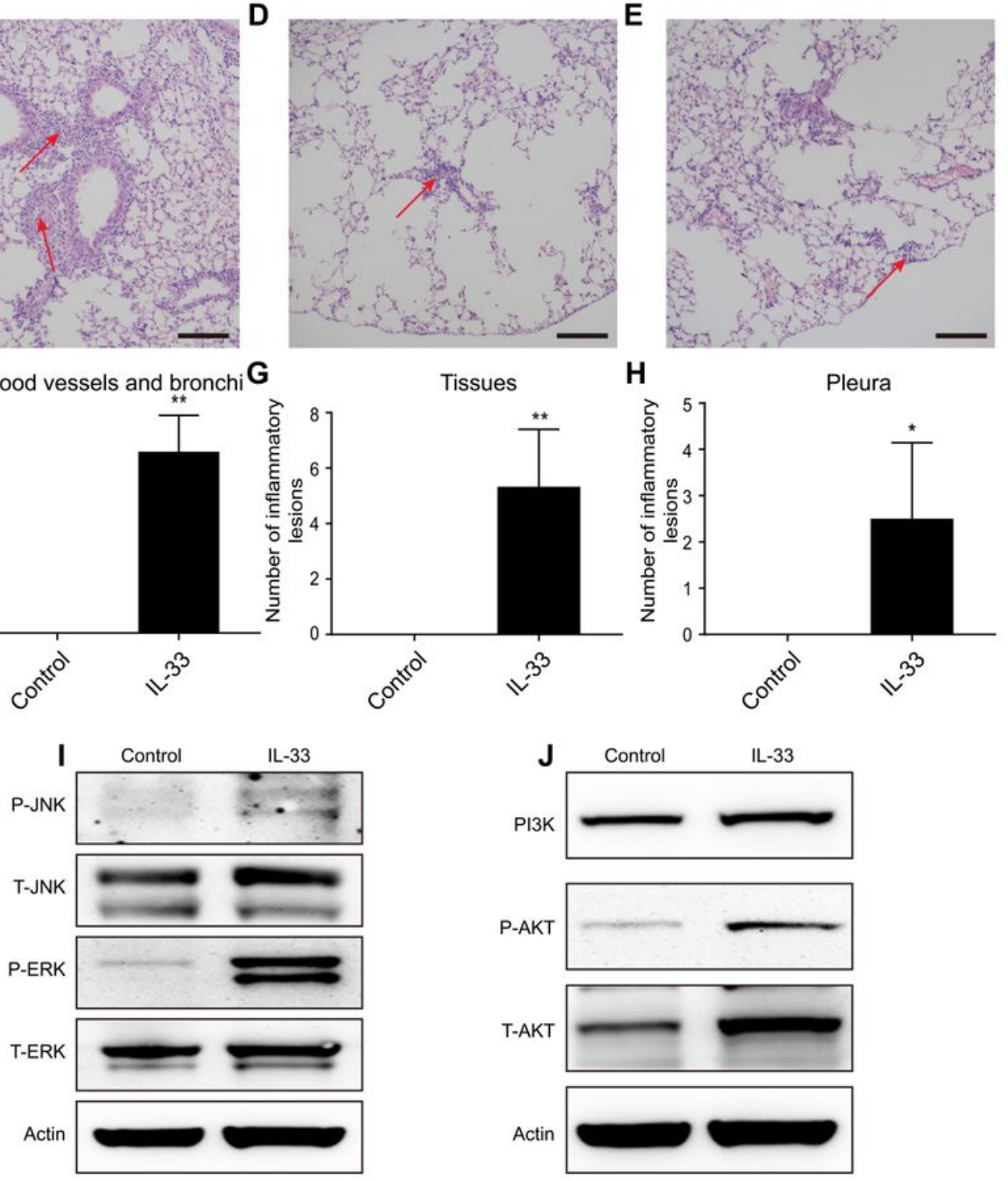

\section{Figure 1}

IL-33 induced lung inflammation through MAPK and PI3K/Akt pathways. Mice were given IL-33 twice a week for four weeks through intratracheal instillation. Total cell counts were examined in BALF (A). Histological analysis of lung damage (H\&E), PBS-treated control group (B), IL-33 treated group among the blood vessel and bronchus (C), tissues (D) and pleura (E). Original magnification was 100X. Histograms demonstrate the number of inflammatory cells in IL-33 treated group compared with the control group (F- 
H) $₫ * \mathrm{P} \llbracket 0.05$ versus PBS control group. The arrow stands for the inflammatory cells. Key proteins of MAPK and PI3k/Akt pathways were determined by western blotting $(\mathrm{I}, \mathrm{J})$.

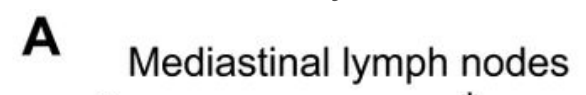

B

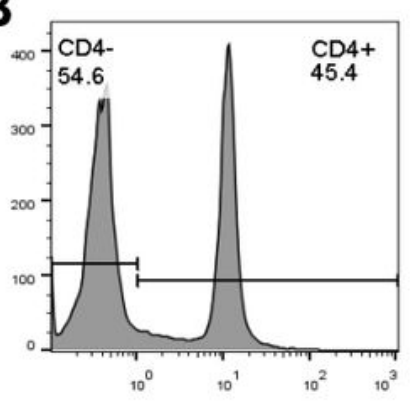

Control

E

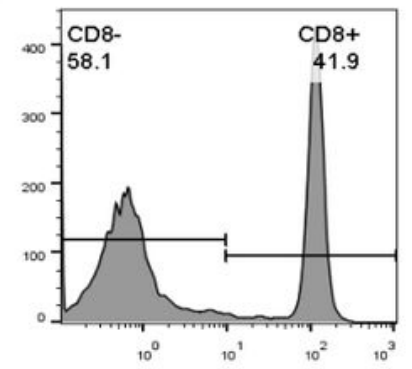

Control

H

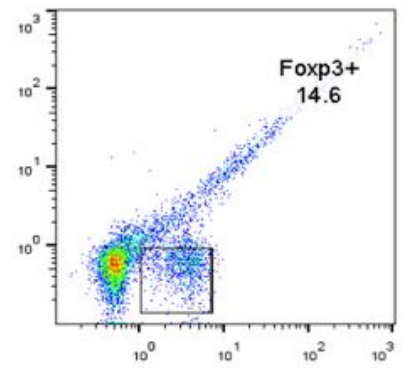

Control

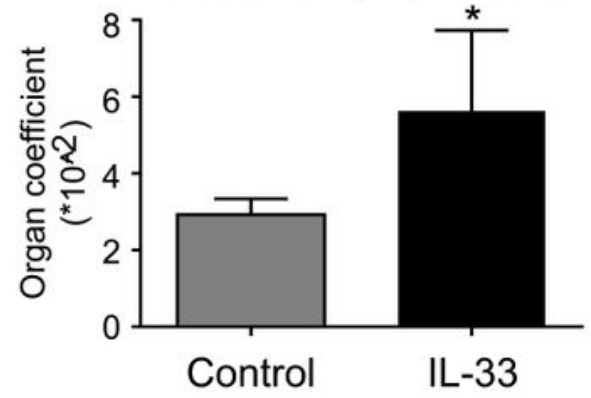

C

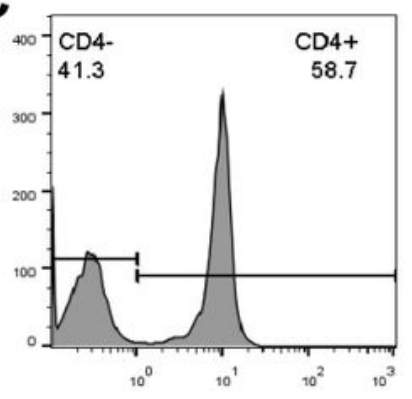

IL-33

$\mathbf{F}$

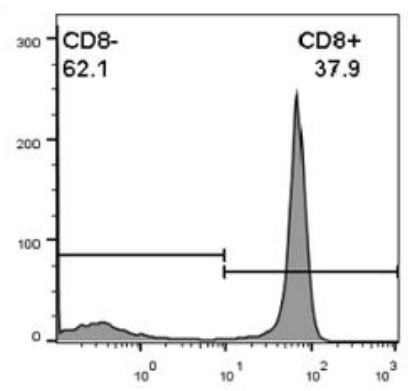

IL-33

I

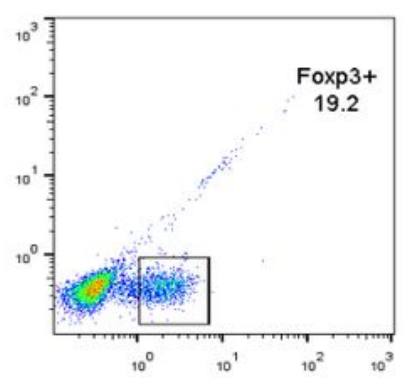

IL-33

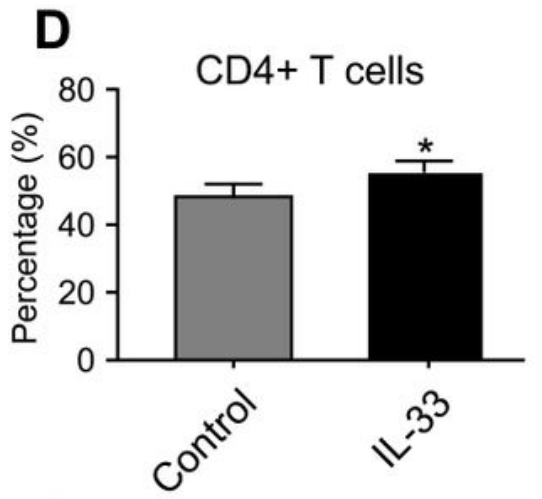

G

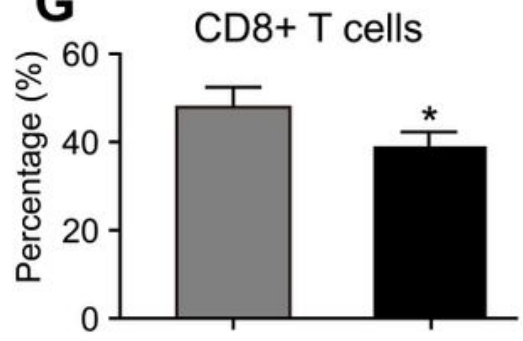

$c^{0 \times 0^{2}} \quad v^{3^{3}}$

Tregs
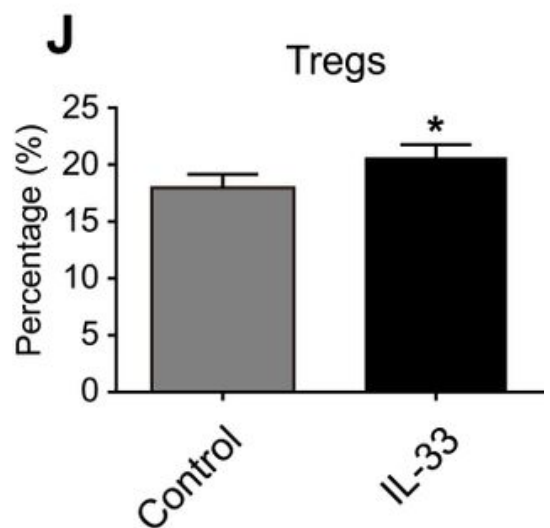

Figure 2

IL-33 changed the T cell sub-types in mediastinal lymph nodes. The coefficient of mediastinal lymph nodes was measured after PBS and IL-33 instillation (A). The T cell sub-types CD4+ (B-C), CD8+ T cells (E$\mathrm{F}$ ) and the Tregs $(\mathrm{H}-\mathrm{I})$ were detected by flow cytometry. The histograms demonstrated the proportion of 
change between IL-33 treated group and the PBS control group, *P『0.05 versus PBS control group (D, G, J).
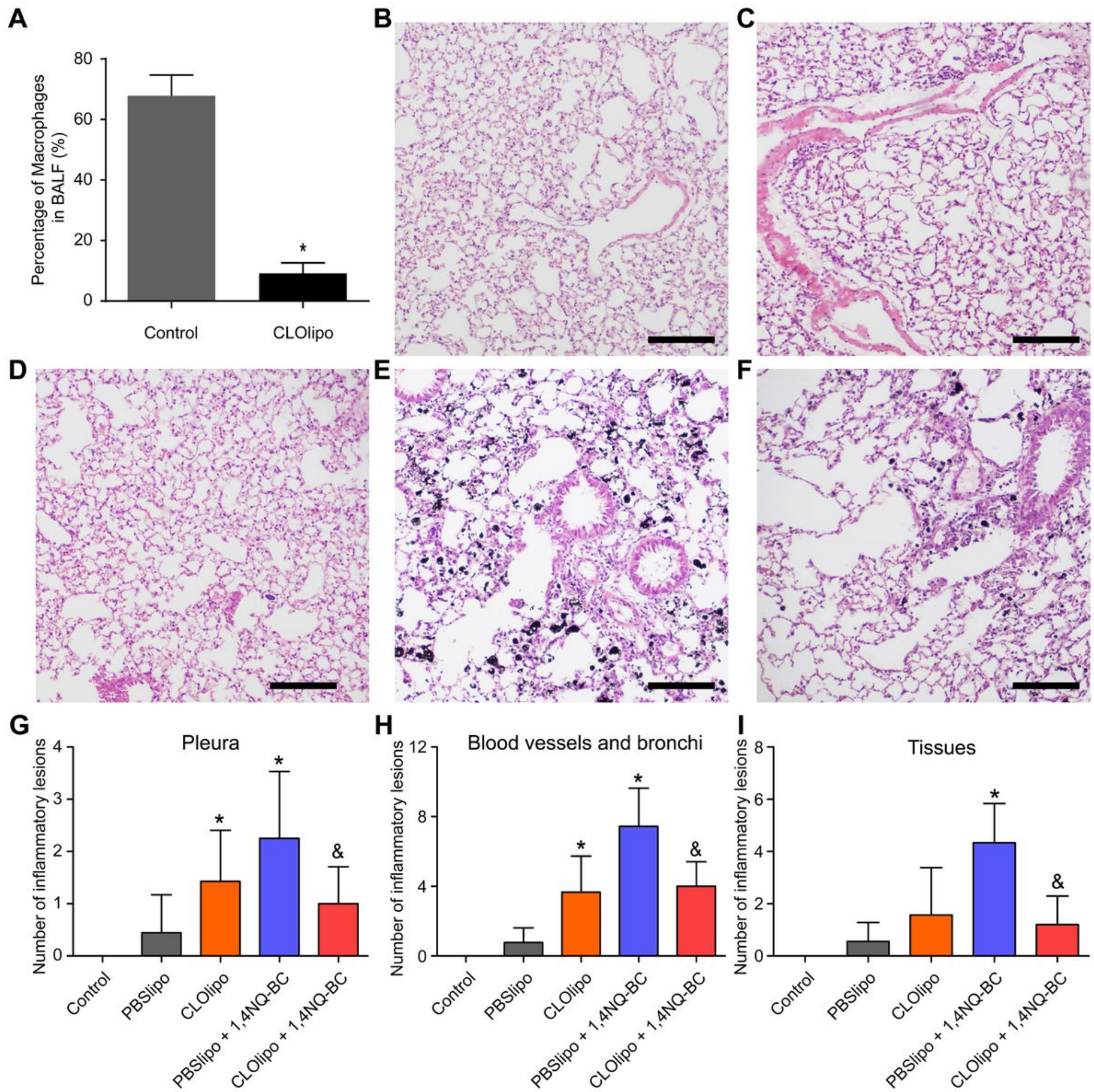

\section{Figure 3}

The lung inflammation caused by 1,4NQ-BC was reversed after elimination of the macrophages. Mice were given PBSlipo, CLOlipo, PBSlipo \& 1,4NQ-NC and CLOlipo \& 1,4NQ-BC twice a week for four weeks through intratracheal instillation. The efficiency of CLOlipo was detected (A). Histological assessment of lung damage (H\&E), the control group (B), the PBSlipo group (C), the CLOlipo group (D), the PBSlipo 

stands for the inflammatory cells. Histograms demonstrate the number of inflammatory cells in different groups among and pleura $(\mathrm{G})$, the blood vessels and bronchus $(\mathrm{H})$ and tissues $(\mathrm{I}),{ }^{*} \mathrm{P}<0.05$ versus PBSlipo group, \& $<0.05$ versus CLOlipo group.

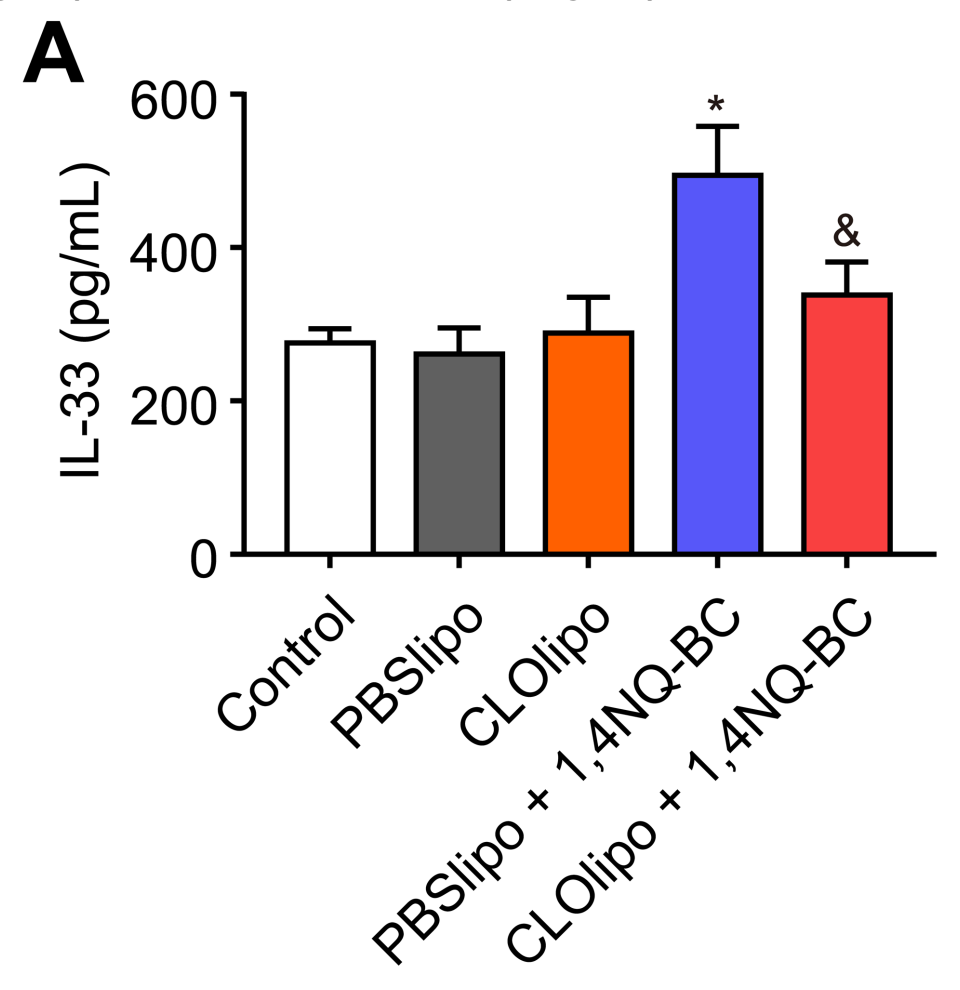

B

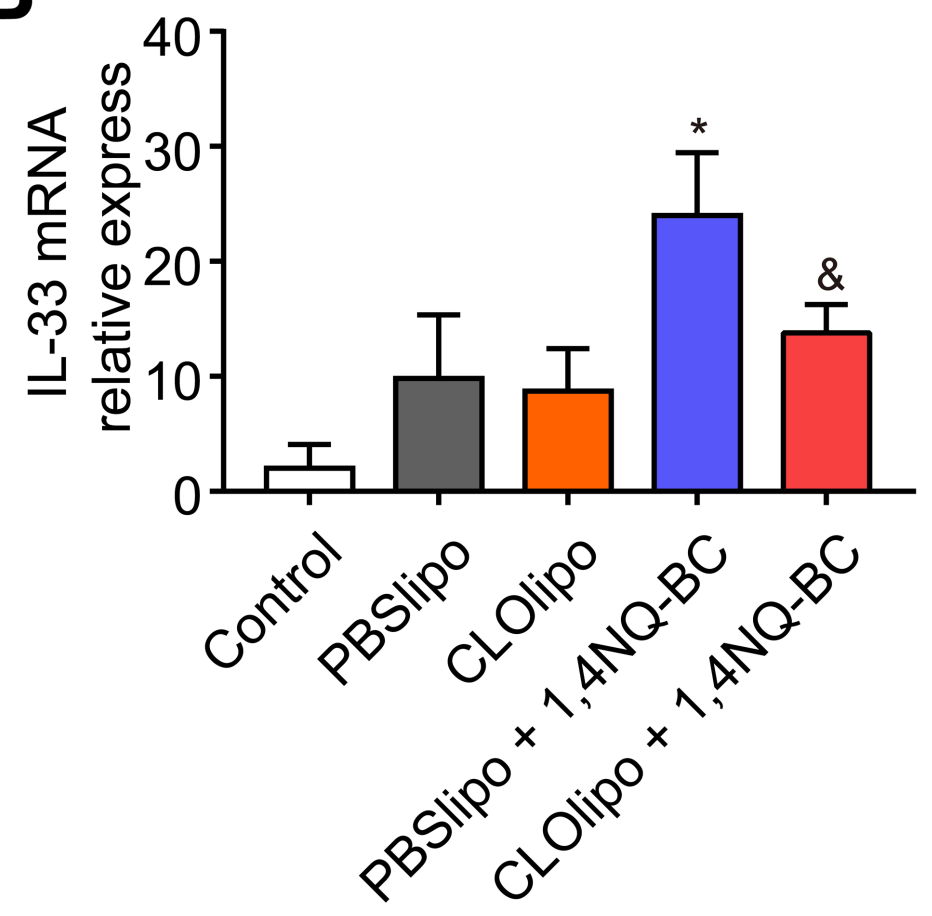

C

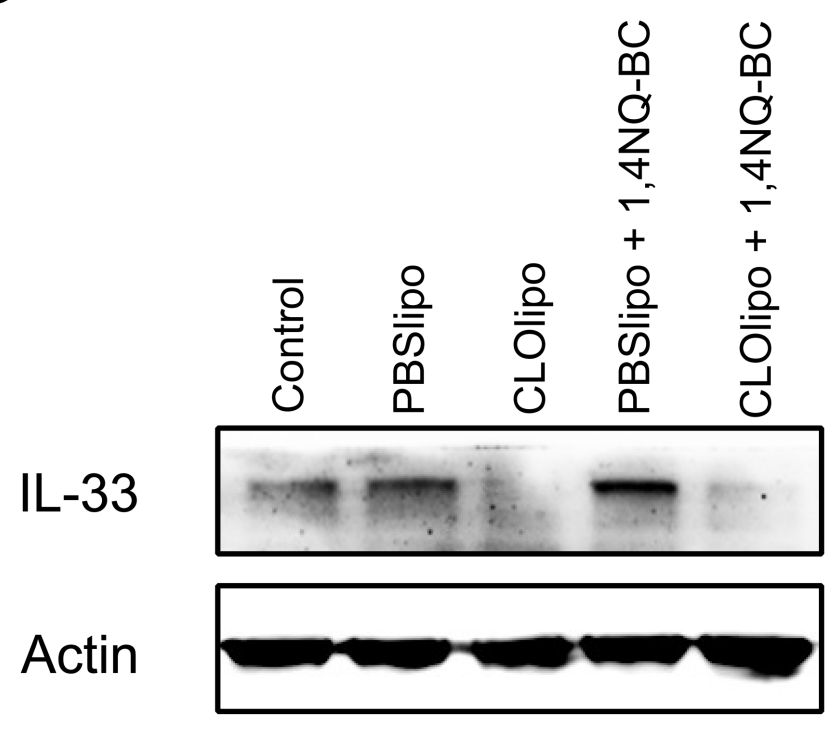

D

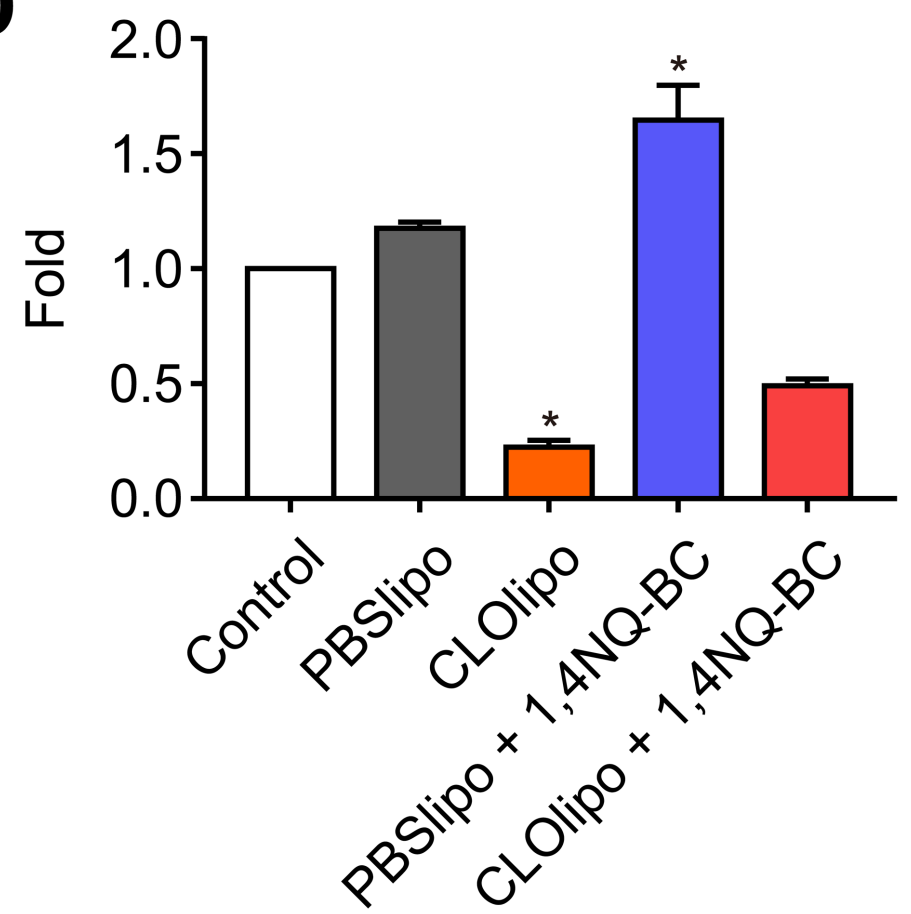

Figure 4 
The secretion of IL-33 was reduced during the elimination of macrophages after exposure to 1,4NQ-BC. The level of IL-33 was detected by ELISA kits in BALF (A). The expression of mRNA (B) and protein (C) of IL-33 in lung tissue were determined by real time PCR and western blots. The fold induction of IL-33 protein was determined by densitometry and normalized to the respective $\beta$-actin level, ${ }^{*} P<0.05$ versus PBSlipo group, \&P<0.05 versus CLOlipo group.

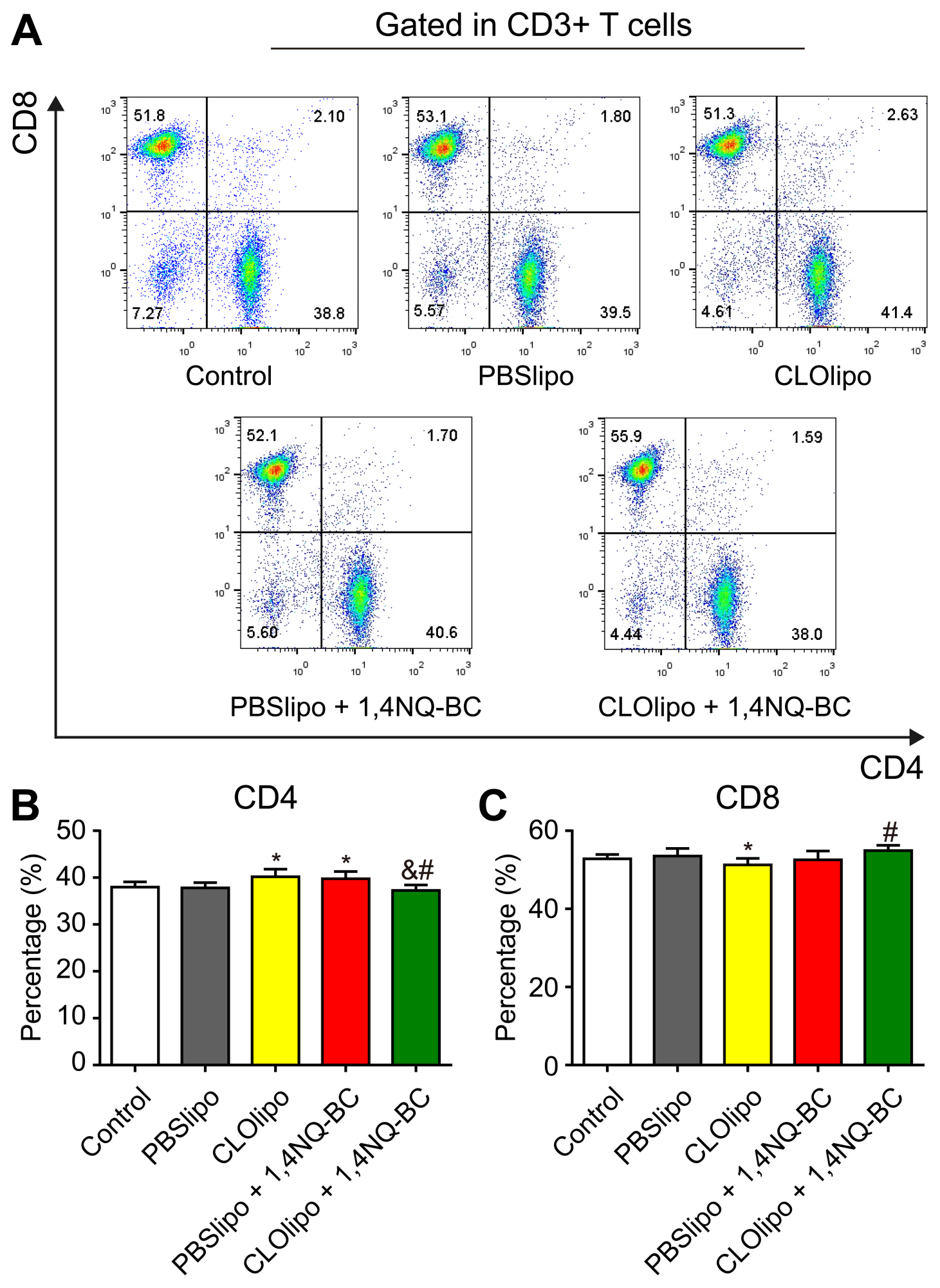

Figure 5 
Deletion of macrophages affected $T$ cell sub-types in mediastinal lymph nodes caused by 1,4NQ-BC. The T cell sub-types $C D 4+(A)$ and $C D 8+(B)$ were detected by flow cytometry. The histograms demonstrated the proportion of change among different groups, ${ }^{*} \mathrm{P}<0.05$ versus $\mathrm{PBSlipo}$ group, $\& \mathrm{P}<0.05$ versus CLOlipo group, $\# \mathrm{P}<0.05$ versus PBSlipo+1,4NQ-BC group.
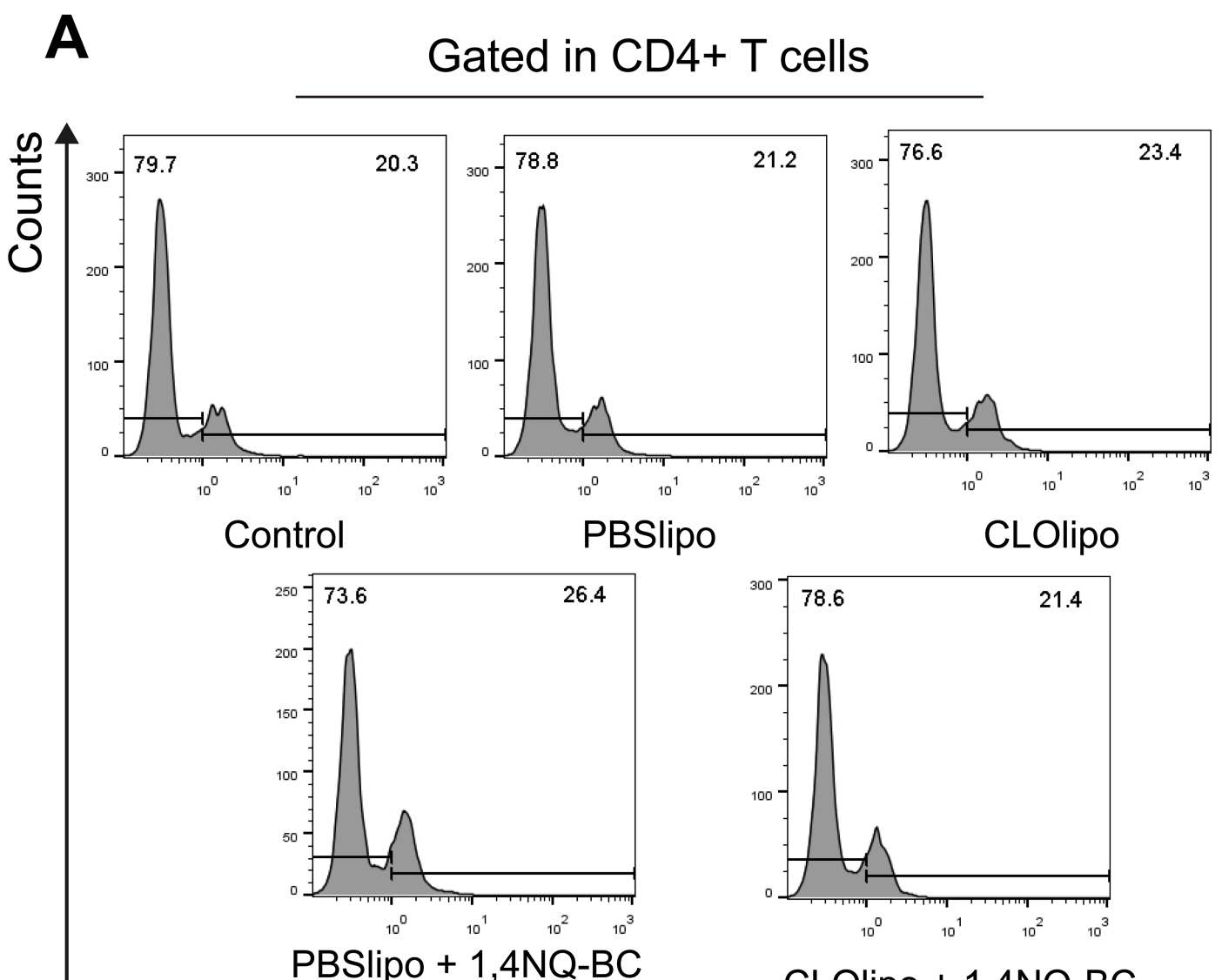

PBSlipo $+1,4$ NQ-BC

CLOlipo + 1,4NQ-BC

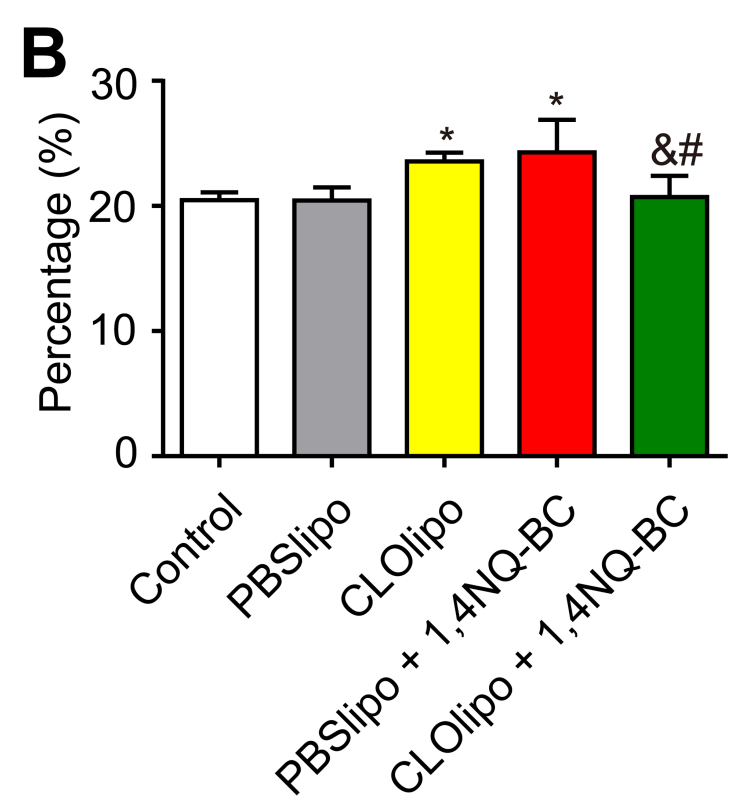

Foxp3

Figure 6 
Deletion of macrophages affected T cell sub-types in mediastinal lymph nodes caused by 1,4NQ-BC. (A) The percentage of Tregs was detected by flow cytometry. (B) The histograms demonstrated the proportion of change among different groups, ${ }^{*} \mathrm{P}<0.05$ versus $\mathrm{PBSlipo}$ group, $\& \mathrm{P}<0.05$ versus CLOlipo group, \# $\mathrm{P}<0.05$ versus PBSlipo+1,4NQ-BC group.
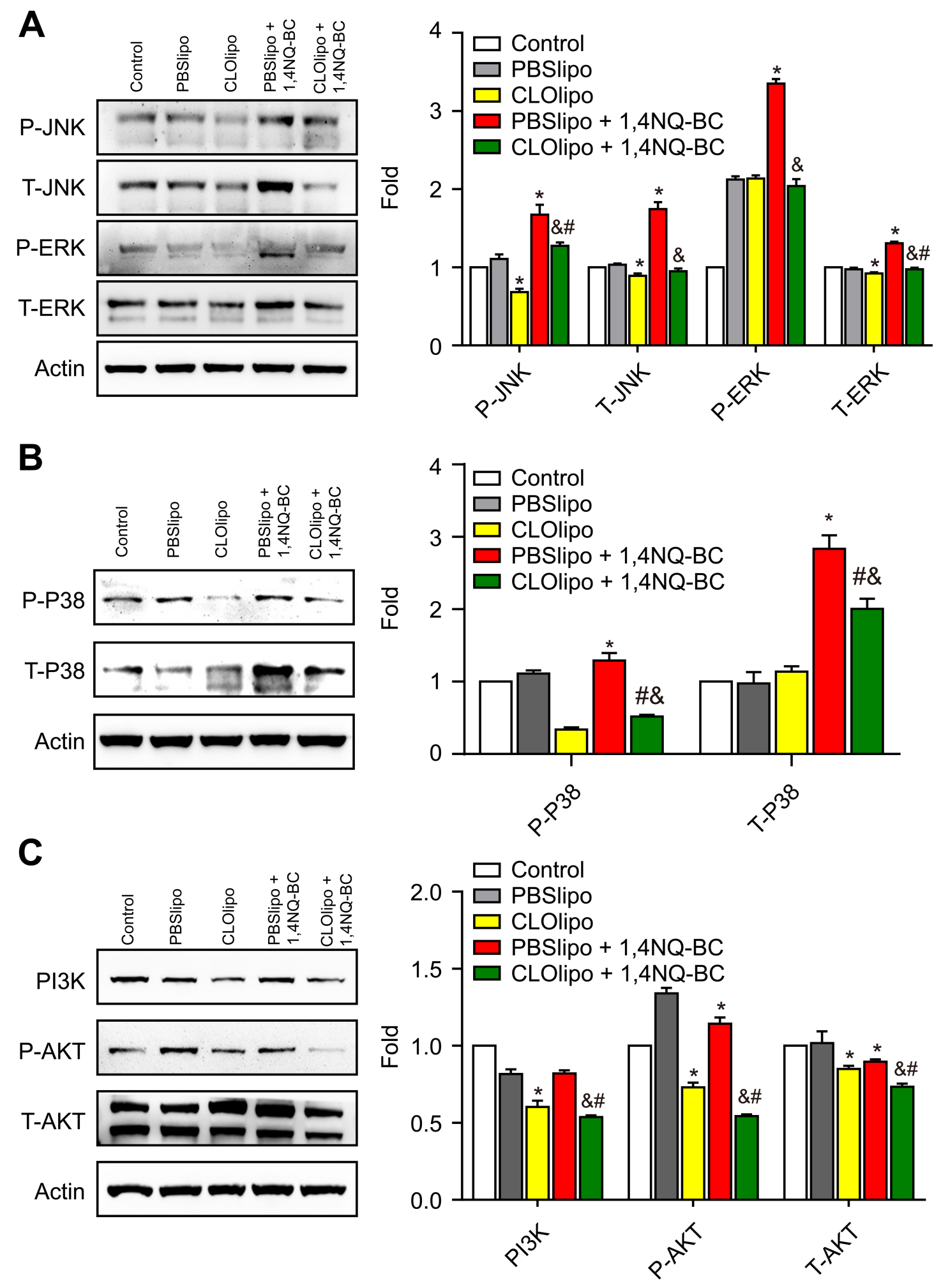

Figure 7 
IL-33 from macrophage might disturb the MAPK and PI3k/Akt signal pathway after 1,4NQ-BC treatment. The expression of related proteins in MAPK $(A, C)$ and $A k t(E)$ pathways in the lung were determined by western blotting. The fold induction of these proteins was determined by densitometry and normalized to the respective $\beta$-actin level, ${ }^{*} P<0.05$ versus PBSlipo group, $\& P<0.05$ versus CLOlipo group, $\# P<0.05$ versus PBSlipo+1,4NQ-BC group. 